\title{
Classification of local anesthesia methods
}

\author{
Arnold Z Petrikas*, Elena V Chestnyh, Denis V. Medvedev and Irina U.Kuritsyna \\ Department of Therapeutic Stomatology, Tver State Medical University, Russia
}

\begin{abstract}
Traditional classification of dental local anesthesia methods must be modified. In our current paper we have proved the vascular mechanism is the leading component of spongy injection. It is necessary to take into account the high effectiveness and relative safety of the spongy anesthesia. We must also take into account its versatility, ease of implementation and the growing prevalence in the world. The essence of the modification is to divide the anesthesia methods into two parts diffuse and vascular- diffuse.

Diffuse anesthesia includes application, infiltration and conduction while vascular-diffuse includes intraosseous, intraligamentary , intraseptal and intrapulpal. For the last four methods we used the term spongy (intraosseous) anesthesia.
\end{abstract}

\section{Introduction}

In medicine anesthesia means a temporary loss of pain sensitivity. This condition, make it possible for operator to work with tissues. Anesthesia can be general and local. In dentistry the main, almost the only way is local injection anesthesia with specific medications - local anesthetics.

The effect of anesthesia is provided by the following mechanism. Using the injector, equipped with a needle, solution of local anesthetic supplies to the outer target (on the mucous membranes of the oral cavity), the needle perforate it and moved forward to internal target, where the injector creates regional anesthetic depot. Depot in the area of the internal target provides an effective concentration of medication and its necessary volume. The volume of anesthetic is very important for moistening of the required number of nerve receptors and nodes of Ranvier. Anesthetic depot and its position is the main element of success.

\section{Method}

To create successful regional depots we need an accurate delivery of solution to the internal target, typically in excess amount. During the blockade of nerves alveolaris inferior (IAN) the position of the internal target is virtual and it depends on many factors, both anatomical and psychological.

The establishment of a depot is possible in two ways: diffuse and vascular. The diffuse method is base of classical injection. Vascular method was presented as an intravenous regional anesthesia in 1908 by A Bier [1].

It is historically mentioned in the General medicine literature. Intraosseous anesthesia of the limbs was arose in the Soviet Union during World War II and was popular (as a military surgeon played two roles - surgeon and anesthesiologist. Freimann SB [2], Krupko et al. [3], Atyasov N [4] had proved its venous mechanism. Dentists also played a role in its appearance [5]. After the war intraosseous anesthesia was very popular, and then it disappeared for more than 20 years. In foreign literature reports about intraosseous anesthesia of the limbs dates back to 1995 with reference to Soviet authors [6].
In dental literature (foreign and Russian) it is believed that vascular dental anesthesia does not exist, there are only variants of diffuse method.

In many dental textbooks and manuals simplest classification of injection anaesthesia is reduced to its separation into infiltration and conduction. Terminology of modern techniques which are commonly used in dental practice is presented in Table 1 .

As rule conduction methods are associated with the blockade of nervous alveolaris inferior (IAN) - it is one of the most difficult problems for stemmatologists. In systematic review Wong [7] determined the complete success of the IAN blockade in molars with a normal pulp (69\%), and molars with irreversibly inflamed pulp (30\%), data was based on electo-testing of the pulp.

Table 1. Classification and terminology methods of local dental anesthesia.

\begin{tabular}{|l|l|l|}
\hline Surface & Infiltration & Conduction \\
\hline Topical & Infiltration & Lower jaw: \\
Application & Local & Mandibular \\
Terminal & Regional & nerve block, \\
Surface & The regional block & IANB \\
& Supraperiostal & Torusal \\
& Subperiosteal & By Egorov \\
& Additional: & At Gow-Gates \\
& Spongy: & By Vazirani-Akinosi \\
& Intraosseous & \\
& Intraligamentary & \\
& Intrseptal & \\
& Intrapulpal & \\
\hline
\end{tabular}

Correspondence to: Petrikas AZ, PhD, DMSc, DM, Professor, Tver State Medical University, 170006, Tver, Belyakovskiy pereulok, 21, Clinic of TSMU, Russia, Tel: 848-223-486-41; E-mail: petrikas2009@rambler.ru

Key words: vascular-diffusion anesthesia, diffusion anesthesia, spongy anesthesia, intraosseous anesthesia, intraligamentary anesthesia, intraseptal anesthesia, supplemental anesthesia

Received: January 16, 2016; Accepted: February 22, 2016; Published: February 26,2016 
Failure of mandibular anesthesia versus to infiltration occurred as a result of the widespread introduction of amide anesthetics, which appeared in Russia in the 80-90s [8]. Failure of conduction anesthesia was permitted by intraosseous, intraligamentary, intraseptal and intrapulpal injections. Hence arose the common term for these methods - "supplemental" or "secondary" anesthesia [9].

This term does not reflect its essential difference from classic methods. From our point of view it is more accurate to use term "spongy", not "supplemental".

Spongy anesthesia of $4 \%$ articaine with epinephrine was highly effective for anesthesia of the pulp especially in lower teeth. It was also shown in our studies of spongy injections - high success rate only in lower teeth, Medvedev DV [10] - 100\%, Efimova [11] - 98.2\%. High efficiency of spongy anesthesia in upper and lower teeth is demonstrated by injection with articaine, epinephrine 1:100000-93\% [12], $2 \%$ lidocaine, epinephrine 1:80000 - 87,1\% [8]. This difference becomes more visible during comparison of these methods with conduction anesthesia $[8,11,13,14]$, accounting for $15-25 \%$. Thus a spongy anesthesia becomes an effective alternative to conduction mandibular injection $[9,15]$.

Intraligamentary anesthesia (ILA) is very popular due to its simplicity. For example, in Bulgaria $76 \%$ of dentists use it during almost all types of interventions [29]. The questioning shows that 800 of the 2,500 American endodontists found that almost $95 \%$ of them use additional methods often ILA - 50\%, and two-stage intraosseous injection [17]. OV Serikova found that $45 \%$ of dentists use it in Voronezh [18].

Operational classification of German authors joins the third type (intraligamentary anesthesia) to principal infiltration and conduction methods [19-21].

The question about the vascular nature of the spongy anesthesia occasionally appeared in the literature in 80 s $[22,23]$. By the beginning of the XXI century this question has not been putted. It presented by only one study [24] and solved in favor of a diffuse mechanism. At the same time, clinicians marked constant heart rate after intraosseous anesthesia and associate it with epinephrine and dose of anesthetic $[25,26]$.

This work presents the analysis of the literature, which indicates the vascular distribution of anesthetic solution during the spongy injection, it explains numerous features. We present the following evidence of the vascular nature of the spongy injections. Most of them already mentioned this in our earlier works [27-30].

Spongy injection of anesthetic combination with adrenaline (presence of adrenalin is important) contains both diffuse and vascular mechanisms of distribution in tissues. Diffuse element works in the first phase of injection, then it pass into the vascular stage during continuing inflow of anesthetic. Vascular stage creates a depot and clinical manifestation of anesthesia. The depot organizes the adrenaline to block patency of capillaries at arteriole level (it became possible through the activation of alpha-adreno receptors (Figure 1).

Bone within spongy substance provided plenty of arteries, veins, venous sinuses, capillaries, which are the cells in the bone, passing one another. Vessels reserved dense bone structure, venous wall tender and delicate. Venous concentration is very high, Injected under pressure into the cell anesthetic solution inevitably erupts in venous spread both blood flow and against it. Reverse flow of blood anesthetic with

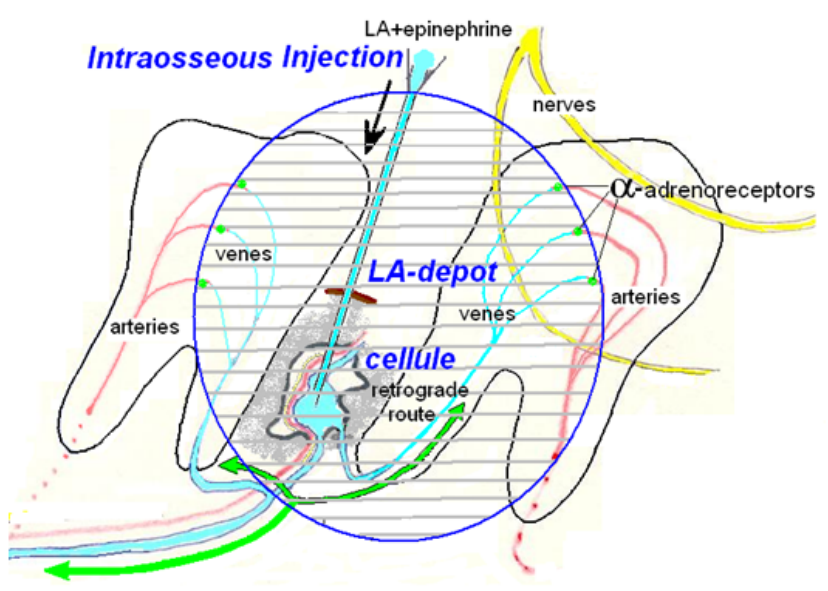

Figure 1. The establishment of an anesthetic depot during spongy anesthesia.

adrenaline reaches arterioles located there with $\alpha$-adrenergic receptors, closing backflow. Emerging regional delay of the injected solution, LAdepot, from which develops anesthesia. The depot is formed from the veins, capillaries and arterioles in part.

1. The presence of adrenaline is necessary for spongy vascular injection [31].

2. During classical injection local anesthetic depot is forming around the needle tip. There is a loss of efficiency to the periphery in geometric sequence. During the spongy anesthesia vascular depot is also associated with the needle. But depot has an indefinite form because it formed by venous vessels reticulum. Some adjacent areas may demonstrate bad loss of sensitivity and, conversely, some distant teeth may have significant anesthetic effect. We called this phenomenon as the mosaic effect of spongy anesthesia [32].

3. As rule depot of spongy distribution covers the periodontium and the pulp of several teeth. On average intraosseous anesthesia blocks 3.2 teeth [12], intraligamentary $-3,6$ teeth [10], intraseptal - 2,6 [11] teeth. The number of the blocked teeth depends on anesthetic dose.

4. The curve of effect/time during the spongy anesthesia differs from classical methods for example infiltration (Figure 2). The essence of the differences is that all kinds of spongy anesthesia starts: 1) immediately under the needle, 2) with a maximum depth and 3) dramatically finished. The law "all or nothing".

Curve effect/time of infiltration anesthesia begins smoothly and ends smoothly; this anesthesia not always reaches the maximum of pain loss. Clinicians appreciate the fast (almost under the needle) onset of anesthesia and its depth during spongy anesthesia.

5. For all spongy anesthesia (intraosseous, intraligamentary and intraseptal) dose of anesthetic is about half as large. Its high efficiency has been presented above. In other words, the efficiency of spongy anesthesia is significantly higher than during traditional injections.

6. During all spongy anesthesia approximately in $90 \%$ of cases we have aspiration " + " [33]. Positive aspiration was observed like a thin stream with a frequency $34 / 36 / 94.4 \%$ and $68 / 76 / 89,4 \%$ during intraligamentary and intraseptal injections respectively.

7. Positive aspirations during intraosseous injection was observed in $68 / 76 / 89,4 \%$. 
8. X-ray distribution of the contrast substance after intraosseous and intercepting injection into the corpses demonstrates the presence of substance in the pulp and in the vessels around the teeth (Figure 3).

9. Histologic pattern after intraseptal injection of staining agent (ink) more clearly demonstrates its venous distribution in the pulp of the tooth, because of good vascular patency of ink versus mercury (Figure 4). During spongy injection ink and mercure almost always find the way to the bones and vessels of the pulp. The penetration of the anesthetic into the vessel does not means development of the effect. Anesthetic activation needs about $40 \mathrm{sec}$ (depot creation) [34].

10. By photoplethysmography was proved the phenomenon of blood flow arrest in the dental pulp at the 15th min after intraligamentary injection of lidocaine with epinephrine [31].

11. Qualitative feature of spongy anesthesia versus classic (for example mandibular anesthesia) is the absence of paresthesia of facial tissues: lips, cheeks, tongue, and skin.

12. Bacteremia was observed in 50-97\% during spongy anesthesia, during buccal infiltration anesthesia was observed in $16 \%$ [35]. Walton $\mathrm{R}$, Abbott B [36] clarify that the frequency of bacteremia during

\section{Pain threshold}

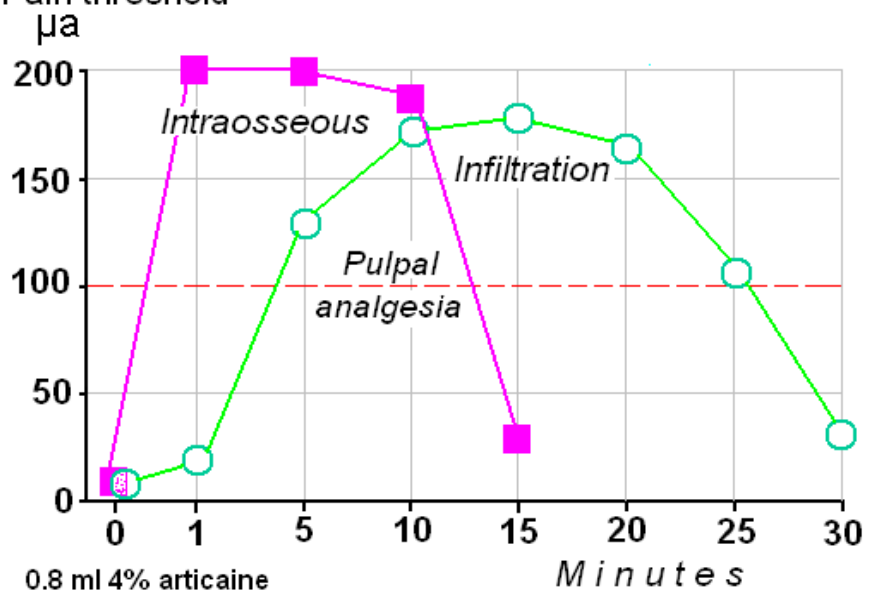

\section{+epiephrine 1:100000}

Figure 2. Spongy anesthesia (continuous): rapid onset (40 sec), maximum effect at the first minute (a super-effect) and dramatically ending.

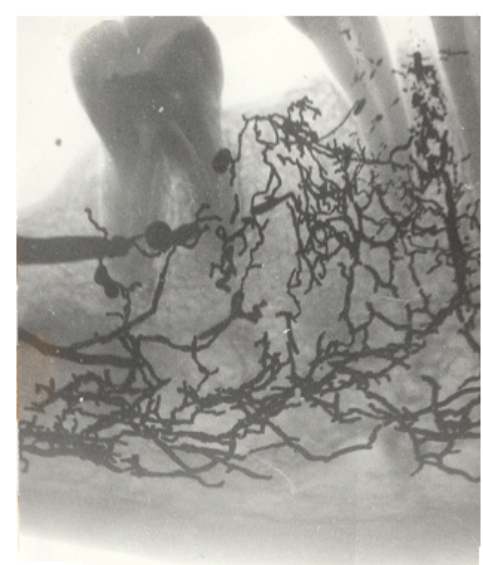

Figure 3. The distribution of mercury in the corpse after intraseptal injection between 44 and 43 .

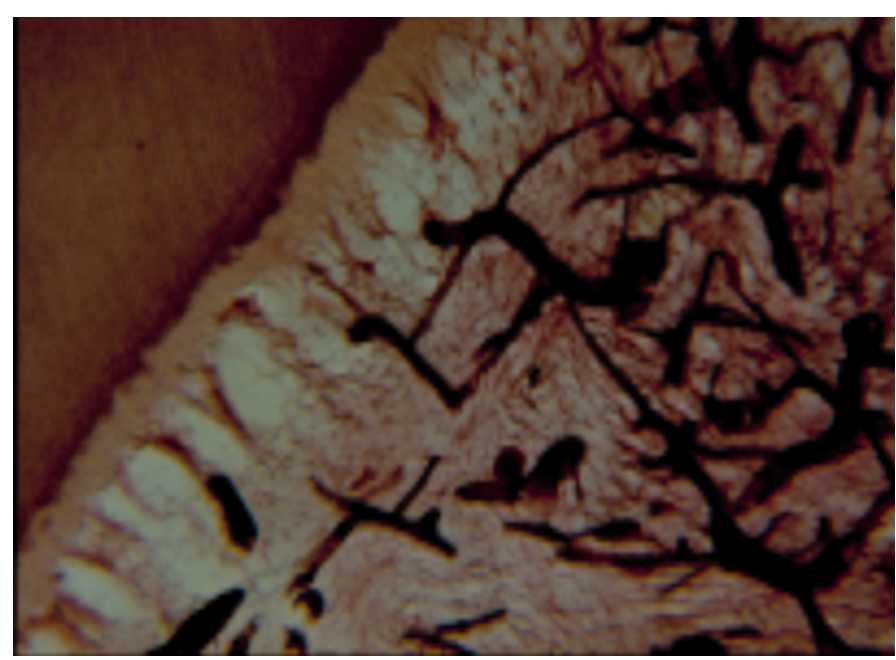

Figure 4. The distribution of staining agent (ink) in the pulp of the tooth after intrasepta anesthesia (corpse of 36 years woman) [8].

intraligamentary injections is the same to other dental procedures. Bacteremia during intraligamentary anesthesia comparable with the same during calculus removing and curettage of periodontal pockets. It is temporary by nature. Antiseptic processing of the gingival sulcus reduces bacteremia from $61 \%$ to $30 \%$ [20].

Heitzmann R, Gabka J didn 't observe bacteremia for more than 10 years of intraligamentary anesthesia using in the clinic. The same data (for 5 year period) was published by Zugal [37]. Injection septicity is important ethical problem for spongy anesthesia in consideration of its vascular mechanism.

13. Vascular distribution of adrenaline during the spongy injections is another threat of complications onset. Analysis of our dissertations about complications: hypotensive (syncope, collapse) or hypertensive (crisis) during spongy and classic anesthesia shows that reaction a little more often was observed during spongy injection versus classic: infiltration $8 / 167 / 4,8 \%$; mandibular $9 / 126 / 7,1 \%$; spongy $56 / 431 / 12,8 \%$ Infiltral/spongy $\mathrm{X}^{2}=9,05$; mandibular/spongy $\mathrm{X}^{2}=0,65$ [38].

In the literature about additional injection technology there is no data about serious systemic complications, except very early work of AJ Boakes et al. [39], which analyzed 12 reports of the Committee on Safety of Medicines (UK) about serious adverse reactions after using of dental anaesthetics with noradrenaline (1:25.000)!. It is interesting that in 2 cases of 12 reactions developed after intraosseous anesthesia - it was very rare in England at that time. Patients had painful headaches immediately after intraosseous injection and after 4-5 minutes. One of them has dizziness, speech and memory disturbance for several days.

We had also observed 3 cases of severe and prolonged headache after intraligamentary anesthesia of articaine and epinephrine solution.

\section{Conclusion}

$>$ In consideration of the leading vascular component of spongy anesthesia mechanism.

$>$ In view of its efficiency and relative safety.

$>$ Having regarded the versatility, simplicity of implementation and increasing prevalence in the world, the traditional classification of local anesthesia needs to be modified. 
Table 2. The essence of the modification is to divide all methods to diffuse and vascular -diffuse.

\begin{tabular}{|c|c|}
\hline \multicolumn{2}{|c|}{ Local anesthesia } \\
\hline Diffuse (traditional) & Vascular - diffuse \\
\hline Topical & Intraosseous \\
\hline Infiltration & Intraligamental \\
\hline Conduction & Intraseptal \\
\hline & Intrapulpal \\
\hline
\end{tabular}

The essence of the modification is to divide all methods to diffuse and vascular -diffuse (Table 2).

Intraosseous, intraligamentary and intraseptal anesthesia can be combined by already existing term "spongy anesthesia". Also we can use outdated term "supplemental methods". It is generally accepted that all of these methods are intraosseous. But usage of this term is not ethical ("I'll make intraosseous injection"). In addition, there will be double term "intraosseous" in the list of spongy anesthesia. The classification does not exclude usage of additional terms: Malamed [9] - supplemental, Noque - diploique, Villette, et al. - diploique, osteocentral, transcortical, Malamed [9] - intraosseous, Marthalerintraseptale. Rabinovich [40] - periodontal, Pollack [41] - spongy, Petrikas [8] - spongy.

We believe that our classification is scientifically, experimentally and practically proved by $90 \%$ and we offer it for application.

\section{Funding}

No external funding was made available for this project.

\section{Statement of conflict of interests}

As far as the authors are aware, there were no conflicts of interests.

\section{Contributions of each author}

AZP planned the conceptual model for the study and its design, analyzed the results, approved the final version.

MDV planned the conceptual model for the study and its design, administered the spongy anesthesia, and analyzed the results. article.

CEV provided set of material, analyzed the result IUK translated

\section{References}

1. Bier A (1908) Ueber einen neuen Weg Lokalanasthesia an den Gliedmassen $\mathrm{Zu}$ Erzeugen. Verh Dtsch Ges Chir 37: 204.

2. Friman BS (1947) Blood Transfusion, anaesthetic and dosage of contrast agents in bone marrow : dis. kand. nayk — Leningrad.

3. Krupko IL, Vorontsov AV, Tkachenko SS (1969) Intraosseous anesthesia. Meditsina: 169.

4. Atyasov N (1970) Intraosseous route of administration into surgical and anaesthetic practice reanimatologists. Gorky: 229.

5. Pollack NL (1936) Spongy anaesthesia. Owls Dent 1: 70.

6. Waisman M, Roffman M, Bursztien S (1995) Intraosseous Regional Anesthesia as an Alternative to Intravenous Regional Anesthesia. J Trauma: Injury, Infection, and Critical Care 39: 695. [Crossref]

7. Wong JK (2001) Adjuncts to Anesthesia: Separating Fakt from Fiction [Text]. J Can Dent Assoc 67: 391-397. [Crossref]

8. Petrikas AZ (1987) Local anaesthesia of the pulp and hard dental tissues: Diss/ Doc med.Sciences. Kalinin : 413.
9. Malamed SF (1982) The periodontal ligament (PDL) injection: An alternative to inferior alveolar nerve block. Oral Surg Oral Med Oral Pathol 53: 117-121. [Crossref]

10. Medvedev DV (2011) Efficacy and safety intraligamentary anesthesia of the pulp and hard tissues of the tooth: dis. kand. nayk-Tver: 27.

11. Efimova OE (2011) Intraseptal anesthesia of hard tissues and pulp of tooth: technique, efficacy, complications: dis. kand. nayk-Tver: 22

12. Yakupova LA (2006) Intraosseous dental anesthesia in experiment and clinic : dis. kand. nayk Tver: 21

13. Yakupova LA, Petrikas AJ (2005) Intraosseous anesthesia teeth (introspection). Clin Dent 4: 50-53.

14. Glockmann E, Dirnbacher T, Taubenheim L (2005) Die intraligamentare Anasthesie Alternative zur konventionellen Lokalanasthesie?. Quintessenz 56: 207-216.

15. AAE: Colleagues for Excellence Winter (2009) ALTERNATEANES THE TIC SOLUTIONS FOR THE INFERIOR ALVEOLAR NERVE BLOCK.

16. Lalabonova HD, Kirova D, Dobreva D (2005) Intraligamentary anesthesia in general dental practice. J IMAB - Ann Proceed 2: 22-24.

17. Kabilov NM (1966) Anesthesia in outpatient dental practice. CRID: 28.

18. Seri ov OV (2013) A results of a poll of doctors on questions of local anesthesia in therapeutic stomatology. Bulletin New Med Technol 2: 437-440.

19. Asanger A, Wendlinger E, Stein C (2006) Местная анестезия в стоматологии. $3 M$ ESPE.

20. Glockmann E, Taubenheim L (2002) Die intraligamentäre Anästhesie. Georg Thieme Verlag, Stuttgart New York, USA.

21. Rahn R, Ball B (2001) Local Anesthesia in Dentistry. Articaine and Epinephrine for Dental Anesthesia. 3M ESPE: 43.

22. Pashley DH (1986) Systemic effects of intraligamental injections [Text]. J Endod 12 501

23. Smith GN, Pashley DH (1986) Systemic effects of intraligamental injections. $J$ Endod 12: 501. [Crossref]

24. Wood M, Reader A, Nusstein J, Beck M, Padget D, et al. (2005) Comparison of intraosseous and infiltration injections for venous lidocaine blood concentrations and heart rate changes after injection of $2 \%$ lidocaine with 1:100,00 epinephrine. $J$ Endod 31: 435-438.

25. http://www.aae.org/

26. Susi L, Reader A, Nusstein J, Beck M, Weaver J (2008) Drum Heart rate effects of intraosseous injections using slow and fast rates of anesthetic solution deposition. Anesth Prog 55: 9-15.

27. Medvedev DV, Petrikas AJ, Dubila MV, Kuritsyn YI (2013) Aspiration in intraligamentous anesthesia. Stomatologiia (Mosk) 92: 19-22.

28. Petrikas AZ, Olkhovskaya EB, Medvedev DV, Diubilo MV (2013) Disputable issue of Malamed's "Handbook of local anesthesia" (2004). Dentistry. Stomatologiia (Mosk) 92: 71-76. [Crossref]

29. Petrikas AZh, Iakupova LA, Medvedev AV, Borodina OE, Egorova VA, et al. (2010) Vascular dental anesthesia and their mechanism. Stomatologiia (Mosk) 89: 66-70.

30. Medvedev D, Petrikas A, Dyubaylo M (2012) Aspiration in intraligamentalanaesthesia of lower first molar teeth: a pilot study. Oral Health Dent Manag 11: 95-99. [Crossref]

31. Kim S (1986) Ligamental injection: a physiological explanation ofits efficacy. $J$ Endod 12: 286 .

32. Medvedev DV, Petrikas AJ (2009) Intraligamentary anesthesia of the lower posterior teeth. Dental 5: 21-23.

33. Petrikas AG, Medvedev DV (2013) during the Aspiration of intraosseous, intraligamentary and intraseptal injections. Endodontics Today 3: 49-53.

34. Suda H (1994) A neurophysiological evaluation of intraligamrntary anesthesia. Den Jpn [Tokyo] 31: 46.

35. Roberts GJ, Simmons NA, Longhurst P, Hewitt PB (1998) Bacteremia following local anaesthetic injections in children. Br Dent $J$ 185: 54-56. [Crossref]

36. Walton RE, Aboott BJ (1981) Periodontal ligament injection: a clinical evaluation [Text]. J Am Dent Assoc 103: 571-575. 
37. Zugal W (2001) Die intraligamentare Anasthesie in der zahnarztlichen Praxis. Zahnarztl Mitt 91: 46-52.

38. Petrikas AG, Medvedev DV, Efimov OE, Yakupova LA, Fair EV (2013) Dental regional spongy (intraosseous) vascular anesthesia [Electronic resource] : monograph / A. J. Petrikas [and others]. Electron Dan Tver.
39. Boakes AJ, Laurence DR, Lovel KW, O'Neil R, Verrill PJ (1972) Adverse Reaction to local anaesthetic/vasoconstrictor preparations. Brit Dent J 133: 137-140.

40. Rabinovich AS (2000) Modern technologies of anesthesia in outpatient dental practice students a whole М. ВУНМЦ МЗ РФ: 144 .

41. Pollack NL (1936) Spongy anaesthesia. Owls Dent 1: 70.

Copyright: $@ 2016$ Petrikas AZ. This is an open-access article distributed under the terms of the Creative Commons Attribution License, which permits unrestricted use, distribution, and reproduction in any medium, provided the original author and source are credited. 